Gregory S. Amacher*-Erkki Koskela**-Markku Ollikainen***

\title{
ROYALTY REFORM AND ILLEGAL REPORTING OF HARVEST VOLUMES UNDER ALTERNATIVE PENALTY SCHEMES****
}

Department of Economics, University of Helsinki

Discussion Papers No 562:2003

ISSN 1459-3696

IBSN 952-10-0705-2

May 21, 2003.

* Department of Forestry, College of Natural Resources, 307 Cheatham Hall, Virginia Polytechnic Institute and State University, Blacksburg, VA 24060, USA. Email: gamacher@vt.edu.

** Department of Economics, P.O. Box 54 (Unioninkatu 37), FIN-00014 University of Helsinki, Finland, and Research Department of the Bank of Finland, P.O. Box 160, 00101 Helsinki, Finland.. Email: erkki.koskela@helsinki.fi.

*** Department of Economics and Management, P.O. Box 27, FIN-00014 University of Helsinki, Finland. Email: markku.ollikainen@helsinki.fi.

**** Koskela thanks the Research Unit on Economic Structures and Growth (RUESG) at the University of Helsinki for financial support and Bank of Finland for hospitality and Ollikainen thanks Academy of Finland for financial support. 


\title{
Royalty reform and illegal reporting of harvest volumes under alternative penalty schemes
}

\begin{abstract}
:
We study royalty reform in a framework where tax evasion or royalty non-payment through underreporting of harvesting is possible, under two alternative penalty schemes. By introducing a revenue-neutral change in royalty progression (or tax regression), we demonstrate several new findings for how actual and reported harvesting change. First, while higher royalty tax progression will always decrease actual harvesting, its effect on reported harvesting is sensitive to the penalty scheme imposed by the government. If the fine is levied on the evaded royalty payments, a rise in revenue-neutral royalty rate progression will increase reporting harvesting. But when the fine is levied on undeclared harvesting, the reverse happens - here, a tax-revenue neutral rise in a lump-sum royalty fee will decrease illegal reporting of harvesting and harvest income. Second, independently of the penalty scheme, an increase in revenue-neutral tax progression will decrease actual harvesting of the concession. The results are important in evaluating recent claims made in the forestry literature regarding reform in royalties for concessions-based forest economies.
\end{abstract}

Keywords: illegal logging, royalty progression, tax evasion, deforestation.

JEL classification: D81, H26, Q23. 


\section{Introduction}

In most of the countries with tropical forests, concessions are the primary means by which timber is sold from government forests (Walker and Smith 1993, Gray 2000). Royalties charged against harvesting of concessions are very important to government revenue collections (Gray 2000, Amacher et al. 2001). ${ }^{1}$ Royalties are typically applied to harvest volumes or values, and can exist in various forms depending on whether they are differentiated or progressive in terms of net harvest rents.

It has been argued that existing royalty systems are poorly-used instruments for either collecting government revenues or promoting sustainable harvesting of concessions (Grut et al. 1991, FAO 1997). The primary criticism is that royalty rates are too low, providing little incentive for reduced harvesting of large concessions, and providing little rent capture for the government (Gray 2000, Vincent 1990, Bushbacker 1990). Governments in tropical countries also inefficiently enforce these tax systems, so that large amounts of harvests are not reported to taxing authorities. These illegal activities further reduce royalty revenue generated by the government and increase net rents to harvesters of concessions (ITTO 2002, Repetto and Gillis 1988).

These criticisms have sparked discussions of reform of royalties in many tropical forest settings. The discussion has thus far has not, however, acknowledged that royalties and government revenue collections are linked, and that both cannot be considered independently of illegal activities such as excess logging or underreporting of harvest volumes. High royalties may appear to be a panacea and a way of increasing government revenues while curbing excess logging, but they can also change the incentive for harvesters to cheat and attempt to evade the

\footnotetext{
${ }^{1}$ For instance, recent interest in Brazil's new concession plan is motivated by the need to raise government collections through a royalty-based charge system (MMA/PPF 2002). Malaysia also has similar interests (FAO 1997).
} 
royalty payments. Cheating is a well-known virtue of concessions when applied in developing countries (ITTO 2002). The probability that harvesters can be caught by the concession-awarding government is also a factor in their illegal activity choices. All of this means that simply calling for higher royalty rates is a problem with no clear solution. It also means that reform in any royalty system is not as simple as raising the royalty rate, like many believe.

In this paper, we focus on commonly suggested royalty reforms in the literature, namely using either higher (unit or ad valorem) royalty rates for harvesting, or using a combination of a royalty rate and a lump sum forest fee or subsidy applied to concessions rights (for a discussion of these suggested reforms, see e.g. Gray 2000). Unlike other work, we investigate these reforms under assumptions that illegal reporting of harvesting might occur. Thus, we will take explicitly into account the interaction of royalties, actual harvesting, and reported harvest volumes in a concessions setting, where the government has decided to allocate a concession of a certain size. There is a positive probability that the government can detect cheating; the probability level may reflect how efficient the government is in observing cheating, or how frequently the government chooses to audit and enforce illegal harvest reporting. Two types of penalty structures are assumed, fines based on evaded (underpaid) royalties for harvesting, and fines levied against undeclared harvest volumes. $^{2}$

A formal model is developed to study whether incentives for illegal logging and actual harvesting can be reduced by a reform in royalty systems. Given the suggested combination of a fee (which could alternatively be a subsidy) and a unit (ad valorem) royalty, a conventional model of tax evasion under progressive (regressive) taxation applies well to our problem. We analyze the suggested royalty reform by changing the royalty systems toward greater or lesser progression (or regression), in a manner that keeps expected government royalty revenue constant. With such

\footnotetext{
2 The specification of fine structures is natural for our tropical forestry problem and has support in other literature on tax evasion (e.g., see Yitzhaki 1974 for penalties levied against evaded taxes and Allingham and Sandmo 1972 for penalties levied on undeclared incomes).
} 
a policy, an increase in the royalty tax rate and the tax exemption level (or an increase in the lump fee and a decrease in the royalty tax rate) means higher progression (regression), in the sense that the average tax rate increases (decreases) more rapidly with increases in the taxable amount (Musgrave and Thin 1948).

We analyze royalty reform in a manner that holds expected royalty collections constant. This requirement is important in providing the incentive for a government, interested in revenue generation, to reform royalties in ways that protect remaining tropical native forests and also reduce illegal harvesting behavior. The importance of ensuring revenue-stability during a reform in policies is clear from the recent literature that establishes a correlation between tropical country debt levels and the rates of deforestation, or literature linking royalties specifically to revenue collection (Poore 1993).

This paper is the first to consider royalty reform under the possibility of illegal reporting of harvest levels. While some researchers have considered incentives for illegal logging at the micro harvesting level (Boscolo and Vincent 2000, Clarke et al. 1993), there is virtually no work that considers royalty reform in the presence of illegal logging, even though there have often been calls to raise royalty rates in the applied literature. Our approach here is closest to work in general public finance theory that considers government tax choices and the potential for tax evasion. Much of this theory has been developed for reform in tax systems where tax evasion is an endogenous function of the tax rate or tax progression chosen by the government (for surveys of the tax evasion literature see e.g. Cowell 1987 and Myles 1995).

We proceed as follows. In section 2 we present the basic framework, including the time sequence of decisions, penalty schemes and tax progression features of the problem, and also provide precursory comparative statics of reported harvesting under alternative penalty schemes. In section 3 we examine the relationship between a tax-revenue neutral change in royalty tax progression and reported harvesting under alternative penalty schemes, while section 4 reports 
results concerning the effect of royalty tax progression on actual harvesting. Finally, there is a brief concluding section.

\section{Basic Framework}

We consider a representative concession and harvester. The concession exists at a point in time and has already been chosen to be a given fixed size. However, the harvester can decide how much of the concession to harvest and how much of an illegal activity to engage in. We study one of the more common forms of illegal activities associated with concessions in practice, i.e., the underreporting of harvest volumes by the harvester to the government. This is a critical problem in tropical countries, as it has been recently estimated that harvest volumes are $80-90$ percent underreported in many countries (ITTO 2002, Gray 2000).

\subsection{Time Sequence of Decisions, Royalty Progression and Penalty Schemes}

Following the order of harvesting and processing, we assume the following time sequence of decisions, depicted in Figure 1. First, the harvester determines the level of actual harvesting, $Q$, once a concession is awarded by the government. Second, once the harvester removes a given amount of volume, it must then decide how much of this to report to the government, $\psi$, thereby determining what its royalty payment obligation will equal. Finally, uncertainty regarding detection or non-detection of cheating by the government is revealed. If the firm is caught cheating, then penalties are imposed. The problem is solved using backward induction.

Figure 1: Time sequence of decisions

\begin{tabular}{lll}
1 & 2 & 3 \\
\hline $\mathrm{Q}$ & $\psi$ & Detection/non-detection
\end{tabular}

(p) 
The harvester takes the timber price $\mathrm{q}$ as given. ${ }^{3}$ Also the probability of detection by the government $p$ and the fine $f$ will be exogenous parameters for the harvester. The first assumption is consistent with the types of small country contexts where the problem of illegal logging is acute. The second assumption is also natural and consistent with other work in natural resource enforcement (Milliman 1986, Sutinen and Anderson 1985).

As the harvester must report a part of actual harvesting to the government, it can be described conveniently by,

$$
Q^{r}=\psi Q
$$

where $Q^{r}$ is the harvest level declared (i.e., reported), $Q$ is actual harvesting within the concession, and $\psi$ is the proportion of actual harvesting that is reported, $0 \leq \psi \leq 1$. A decrease in $\psi$ represents an increase in royalty evasion.

The government manages the concession and imposes a royalty against volume harvested by the firm. The firm pays the royalty once it harvests and declares reported harvest volume. We assume the following structure for this volume-based royalty,

$$
t(\psi Q-r)
$$

where $t$ is the royalty rate, $\psi Q$ is the volume of timber reported to the government from concession, and $r$ is an exemption level determined by the government, i.e. the amount of reported volume not subject to the royalty charge. ${ }^{4}$ Note that this volume-based royalty could easily be given as a value-based royalty using timber price and applying the royalty against the value of timber harvested from the concession. In practice royalties applied to concessions often

\footnotetext{
${ }^{3}$ This is the most common assumption. An exception is Marrelli 1984, who uses a simple model of monopolistic behaviour to study the relationship between tax evasion and tax incidence.

${ }^{4}$ As will be seen later on, a combination of a royalty tax and a lump-sum fee yielding a regressive tax system can be obtained from (2) by assuming that $r$ is negative and independent of the royalty rate, so that tax revenue with reported harvesting is $t \psi Q+r$ (for the details, see Appendix 4).
} 
appear in the form of (2). ${ }^{5}$ The form in (2) is also convenient in that it allows us to examine a specific royalty progression. ${ }^{6}$ Consider that a simultaneous increase in the tax exemption $r$ and the royalty tax rate $t$ is equivalent to an increase in royalty progression, in the sense that the average tax rate increases more rapidly in the tax base.

If the harvester is detected cheating a fine penalty is imposed. Suppose the government levies the penalty with a fine rate of $f$. This fine rate is exogenous and is determined by laws. It is applied to harvesters who are caught evading royalty payments through underreporting of harvested volume. ${ }^{7}$ We will consider two alternative penalty schemes that cover two possible infractions involved with misreporting harvests once a cheater is caught. The first is a penalty levied against the amount of the royalty that the cheating harvester evades. In this case the penalty is written $f t Q(1-\psi)$. The second is a fine levied against undeclared harvest volume, so that the penalty is written $f Q(1-\psi){ }^{8}$

The harvester's profits depend on harvesting, the illegal activity, the probability of detection, and the penalty scheme if caught cheating. Let $q$ be the timber price and $C(Q)$ be a convex cost of harvesting, i.e., $C^{\prime}(Q)>0 ; C^{\prime \prime}(Q)>0 .^{9}$ First, consider the case where the penalty is levied on the evaded royalty payment. If harvester is not detected cheating, then its net rents are given by (3), but if the cheating firm is caught and the penalty is enforced, then its net rent is given by (4),

\footnotetext{
${ }^{5}$ This is the case in many tropical forest countries, including Indonesia, the Philippines, and parts of Latin America (Gray 2000, Vincent 1990, Amacher et al. 2001). The royalty considered here is similar in spirit to an 'area royalty' if we think of a concession in terms of total volume of harvest in a given area. In this case, some quantity of harvest volume is usually exempted from the tax payment made by the harvester. Many concessions have been applied in this manner.

${ }^{6}$ For a discussion of various forms of tax progression, see the classic paper by Musgrave and Thin (1948). See also chapters 6-8 in Lambert (1993) for a further analysis.

${ }^{7}$ Our inclusion of an exogenous fine is consistent with the observation that fines are typically set by the legal sector. This is a common assumption in the environmental economics literature where fines and enforcement of polluting firms are studied.

${ }^{8}$ The implications of these penalty schemes have been studied in a different context by Koskela (1983).

${ }^{9}$ In what follows, derivatives of functions with one argument are denoted by primes, while partial derivatives of a function with two or more arguments are denoted by subscripts of the parameter we are differentiating with respect to.
} 


$$
\begin{aligned}
& Y=Q(q-t \psi)-C(Q)+t r \\
& Z=Y-f t Q(1-\psi)
\end{aligned}
$$

The second case, where the penalty is levied on undeclared harvest volume, will be denoted using a superscript $u$. Thus, the rents to the harvesters are given by (5) and (6) for the cases when the harvester is not caught and is caught, respectively:

$$
\begin{aligned}
& Y^{u}=Q^{u}\left[q-t \psi^{u}\right\rfloor-c\left(Q^{u}\right)+t r \\
& Z^{u}=Y^{u}-f Q^{u}\left(1-\psi^{u}\right) .
\end{aligned}
$$

Finally, we make the conventional assumption about preferences for risky behavior by the harvester. We assume that the harvester is risk-averse, so that he maximizes the expected utility of harvest revenue by choosing actual and reported harvest volumes. Armed with these definitions and assumptions we now solve the first and the second stage of the model in the next two subsections.

\subsection{The Choice of Reported Harvest Volume under the Penalty Scheme Levied on the}

\section{Evaded Royalty}

Using backward induction, we first solve the second stage, where the harvester chooses the extent of their illegal activity via the choice of reported harvesting $\psi$, taking actual harvesting from the first stage as exogenous. The harvester chooses reported harvest volume to maximize expected utility, $E U(\pi)=(1-p) U(Y)+p U(Z)$. 
The first order condition for reported harvesting when the penalty rate $f$ is levied against the amount of the evaded royalty payment is,

$$
E U_{\psi}=-(1-p) U^{\prime}(Y)+p(f-1) U^{\prime}(Z)=0 .
$$

A condition for an interior solution, where the firm does cheat, requires,

$$
\left.E U \psi\right|_{\psi=1}=-(1-p) U^{\prime}(Y)+p(f-1) U^{\prime}(Z)<0 \Leftrightarrow(1-p f)>0 .
$$

This condition makes sense, because if the expected fine $p f$ were equal to one, then the harvester would not have an incentive to underreport harvest volumes, and then $\psi=1$. Using the first order condition (7), and assuming now that cheating indeed occurs $(\psi<1)$, we can show that an interior solution requires the following condition,

$$
p(f-1)=\frac{(1-p) U^{\prime}(Y)}{U^{\prime}(Z)}
$$

Equation (9) shows that the harvester sets the ratio of marginal utilities for cheating and not cheating equal to the expected fine minus the detection probability. The second-order condition holds and is given in the Appendix 1.

The first order condition for reported harvesting when the penalty rate $f$ is levied against undeclared harvesting is,

$$
E U_{\psi^{u}}=-(1-p) t U^{\prime}\left(Y^{u}\right)+p(f-t) U^{\prime}\left(Z^{u}\right)=0 .
$$


An interior solution requires that,

$$
\left.E U_{\psi^{u}}\right|_{\psi^{u}=1}=-(1-p) t U^{\prime}(Y)+p(f-t) U^{\prime}\left(Z^{u}\right)<0 \Leftrightarrow(t-p f)>0,
$$

which can be interpreted analogously to equation (8). Equation (11) requires that the expected fine $p f$ must be less than the royalty rate $t$ paid by the harvester if volume is declared. If these are equal then the harvester will never cheat. We show in Appendix 1 that the second order condition holds.

As a precursor to further analysis, we must determine how the harvester's decision to underreport harvest volume depends on parameters such as actual harvesting, the royalty rate, and the royalty exemption level. A summary of comparative statics results for these parameters are presented in Table 1 and derived in Appendix 2. As Table 1 shows, in the second stage the solutions to (7) and (10) define an optimal choice of royalty evasion, through the choice of reported harvesting, as a function of actual harvest level in stage 1 , the royalty rate, and the royalty exemption level, $\psi \equiv \psi(Q, t, r)$ and $\psi^{u} \equiv \psi^{u}(Q, t, r)$.

The results in Table 1 are partly sensitive to risk aversion behavior. Under decreasing absolute risk aversion (DARA) and a penalty levied against the evaded royalty, reported volumes increase as either the royalty rate is increased, actual harvest levels increase, or the royalty exemption

Table 1: Comparative Statics of Reported Harvest Volume

\begin{tabular}{|l|cc|cc|}
\hline Parameter & \multicolumn{2}{|l|}{ Penalty on Evaded Royalty } & \multicolumn{2}{|l|}{ Penalty on Undeclared Harvesting } \\
& CARA & DARA & CARA & DARA \\
\hline Royalty Rate $(\mathrm{t})$ & + & + & - & $+/-$ \\
\hline Royalty Exemption $(\mathrm{r})$ & 0 & - & 0 & - \\
\hline Actual Harvesting $(\mathrm{Q})$ & + & + & + & + \\
\hline
\end{tabular}


level increases. These results are due to the negative income effects of the royalty rate on reported harvest levels, while the positive income effect is due to the higher royalty exemption level.

The results remain qualitatively the same for the royalty rate and actual harvesting under constant absolute risk aversion (CARA), but now the royalty exemption level has no effect on reported harvesting. Finally, when the penalty is levied on undeclared harvesting, the effects of actual harvesting and royalty exemption levels on reported harvesting are qualitatively similar, but the effect of the royalty rate is now ambiguous.

\subsection{The Choice of Actual Harvest Volume under Alternative Penalty Schemes}

When choosing the actual level of harvesting in the first stage, the harvester takes the optimal value of reported harvesting as given and maximizes his indirect expected utility function. When the fine is levied on evaded royalties expected indirect utility is written,

$$
\underset{Q}{\operatorname{Max}} E U^{*}=(1-p) U\left(Y^{*}\right)+p U\left(Z^{*}\right)
$$

where ${ }^{*}$ denotes an indirect utility function and $\psi$ has been set to its optimal level, $\psi^{*}$, so that $Y^{*}$ and $Z^{*}$ are given by (2) and (3) with $\psi=\psi^{*}$. Using the envelope theorem, ${ }^{10}$ the first order condition for (12) becomes,

$$
E U_{Q}^{*}=0=(1-p) U^{\prime}\left(Y^{*}\right) \hat{a}+p U^{\prime}\left(Z^{*}\right) \hat{b}
$$

where $\hat{a}=q-C^{\prime}(Q)-t \psi^{*}>0$ and $\hat{b}=q-C^{\prime}(Q)-t\left(\psi^{*}+f\left(1-\psi^{*}\right)\right)<0$. The second order condition is given in Appendix 1.

\footnotetext{
${ }^{10}$ Here, the envelope theorem guarantees that the indirect effect of harvesting vanishes, i.e. $E U_{\psi} \psi_{Q}=0$.
} 
When the penalty for cheating is levied based on undeclared harvesting, the harvester's problem is to maximize,

$$
\underset{Q^{u}}{\operatorname{Max}} E U^{u^{*}}=(1-p) U\left(Y^{* u}\right)+p U\left(Z^{* u}\right)
$$

where $Y^{* u}$ and $Z^{* u}$ are defined by (5) and (6) with $\psi=\psi^{*}$. The first order condition for the harvester's choice is: $E U_{Q^{u}}^{u^{*}}=E U_{Q^{u}}^{*}+E U_{\psi^{u}}^{*} \psi_{Q u}^{u}$. The second RHS term is zero using the envelope theorem, and thus we can write,

$$
E U_{Q u}^{u^{*}}=0=(1-p) U^{\prime}\left(Y^{u}\right) \widetilde{a}+p U^{\prime}\left(Z^{u}\right) \tilde{b}
$$

where, $\widetilde{a}=q-C^{\prime}\left(Q^{u}\right)-t \psi^{* u}>0$ and $\tilde{b}=q-C^{\prime}\left(Q^{u}\right)-\left(t \psi^{* u}+f\left(1-\psi^{* u}\right)\right)<0$.

The comparative statics for actual harvesting in terms of the royalty rate and the royalty exemption under the two alternative penalty schemes are derived in Appendix 3 and presented in Table 2.

Table 2: Comparative Statics of Actual Harvest Volume

\begin{tabular}{|l|cc|cc|}
\hline Parameter & \multicolumn{2}{|c|}{$\begin{array}{l}\text { Penalty on Evaded Royalty } \\
\text { CARA }\end{array}$} & \multicolumn{2}{|c|}{$\begin{array}{l}\text { Penalty on Undeclared Harvesting } \\
\text { DARA }\end{array}$} \\
\hline Royalty Rate $(\mathrm{t})$ & - & - & - & DARA \\
\hline Royalty Exemption $(\mathrm{r})$ & 0 & + & 0 & - \\
\hline
\end{tabular}

In the case of DARA the royalty rate will have a negative effect on actual harvesting, but the royalty exemption level will have a positive effect under both penalty schemes. This can be interpreted as follows. Under DARA the royalty rate will have a negative substitution and a negative reinforcing income effect, while the royalty exemption level will have a positive income 
effect. Under CARA, the income effects will vanish so that the royalty exemption level will have no effect, but the royalty rate will have a negative substitution effect.

The findings presented in Tables 1 and 2 turn out to be important for our policy reform analysis to follow. The impacts of royalties and exemption levels on cheating and actual harvesting depend not only on risk preferences, but also on the nature of penalty schemes. For decreasing absolute risk-aversion we have

Proposition 1. In the case of DARA, if the penalty rate is levied against the evaded royalty payments, then a higher royalty rate reduces actual harvesting but increases reported harvesting, thus decreasing illegal activities. The effect of the royalty rate is ambiguous when the penalty is levied against undeclared harvesting. In both cases higher royalty exemption levels increase actual harvesting but decrease reported harvesting.

Interestingly, higher royalty rates and royalty exemptions work in opposite directions. As we will demonstrate in the next two sections, their overall effects under royalty reform will therefore depend on the penalty scheme, and sometimes (but not always) one should use the royalty fee instead of a royalty exemption - to increase reported harvesting as the literature on royalties suggests.

\section{Tax-Revenue Neutral Royalty Progression and Reported Harvesting}

Now we examine the consequences of alternative penalty schemes for royalty policy reform. Recall our initial interest was to examine royalty reform towards progression (regression) under two conditions, 1) the government is interested in revenue generation and wishes to keep expected revenue collection constant, and 2) illegal reporting of harvest volumes occurs and can undermine government revenue collections. Hence, the specific policy question we answer in this section is: What is the effect on reported harvesting of an increase in the royalty tax rate and 
royalty exemption, done in a manner that holds constant expected royalty revenue collections of the government?

\section{A. Penalty Charged on Evaded Royalty Payments}

The social planner's expected tax revenue, when the penalty rate is levied against the evaded royalties, can be written,

$$
R^{e}=t Q[\psi+p f(1-\psi)]-t r
$$

The first term in brackets is the expected royalty revenue collected from reported harvesting, and the second term is expected revenues derived from penalties charged against evaded harvest volumes (if the harvester is caught with probability $p$ ). To examine reform in the royalty system that holds revenue constant we first totally differentiate (16) with respect to policy instruments $r$ and $t$, and reported harvesting $\psi$, to obtain

$$
\left.d r\right|_{d R^{e}=0}=\frac{R^{e}}{t^{2}} d t+Q(1-p f) d \psi
$$

The total effect of the royalty rate and royalty exemption on reported harvesting can then be expressed as

$$
d \psi=\psi_{t} d t+\psi_{r} d r
$$

Substituting $d r$ from (17) into the RHS of (18) gives the effect of changing royalty progression on reported harvesting, holding expected tax revenue constant,

$$
\left.\frac{d \psi}{d t}\right|_{d R^{e}=0}=\frac{\psi_{t}+\psi_{r} \frac{R^{e}}{t^{2}}}{\left[1-\psi_{r}(1-p f) Q\right]} .
$$


From Table 1, we know that $\psi_{r} \leq 0$, and at an interior solution for reported harvesting, 1-pf $>0$ must hold from (8). Thus the denominator of (19) is positive.

The numerator must be examined more closely to determine its sign. First we write the numerator in terms of absolute risk aversion, $A(.) \equiv-U^{\prime \prime}(.) / U^{\prime}($.$) . Under DARA, A^{\prime}()<$.0 and $\mathrm{Y}>\mathrm{Z}$ implies $\mathrm{A}(\mathrm{Y})<\mathrm{A}(\mathrm{Z})$, while under $\mathrm{CARA}, A^{\prime}()=$.0 and $\mathrm{A}(\mathrm{Y})=\mathrm{A}(\mathrm{Z})$. Using these definitions, under DARA the numerator term is positive, i.e.,

$\psi_{t}+\psi_{r} \frac{R^{e}}{t^{2}}=\frac{r[A(Z)-A(Y)]+A(Y) p f(1-\psi) Q+A(Z)(1-\psi) f(1-p) Q}{t Q[A(Y)+(f-1) A(Z)]}>0$.

Under CARA, we previously showed that underreporting of harvesting is not sensitive to the royalty rate $\psi_{r}=0$, and therefore equation (20) simplifies to,

$\psi_{t}+\psi_{r} \frac{R^{e}}{t^{2}}=\frac{p f(1-\psi)+(1-\psi) f(1-p)}{t f}=\frac{(1-\psi)}{t}>0$

Returning to (19), we have therefore shown that $\left.\frac{d \psi}{d t}\right|_{d R^{e}=0}>0$. Summarizing, we have,

Proposition 2. Under a penalty scheme where the fine is charged against the evaded royalty payments, higher royalty progression, implemented to keep expected royalty collections constant, will increase reported harvesting and thereby decrease cheating.

The result in Proposition 2 shows an interesting policy result. The government can reduce underreporting of harvest volumes if royalties are reformed toward higher progression, even when it is done in a manner that holds government revenue collections constant. Thus, the revenue needs of the government and the need to keep cheating controlled are compatible with 
higher progression under this penalty scheme. Intuitively, when the penalty rate is charged on evaded royalty revenues, the royalty rate and the royalty tax exemption will induce positive and negative income effects, respectively, but the positive income effect dominates for the harvester. Thus, the firm facing this type of penalty will increase reported harvesting, and illegal activities will decrease.

This result runs counter to the literature's recommendation of using a combination of a forest fee on the concession right and a royalty rate. We have shown that a subsidy, and not a fee, leading to progressivity of the royalty rate is needed to control cheating when the penalty rate is charged on evaded royalty revenues. The difference in our result and the recommendation from the literature is our explicit consideration of cheating and penalty schemes.

\section{B. Penalty Charged on Undeclared Harvest}

As above we again return to our policy question under this alternative penalty scheme: What is the effect of a change in tax progression on reported harvesting, undertaken in a manner that holds expected royalty collection revenues constant, when penalties are levied on undeclared harvesting? The government's expected revenues for this penalty case are,

$$
R^{e u}=Q^{u}\left[t \psi^{u}+p f\left(1-\psi^{u}\right)\right]-t r .
$$

Taking the total derivative with respect to policy instruments and reported harvesting, in a manner that holds expected revenue constant, yields

$$
\left.d r\right|_{d R^{e u}=0}=\frac{\psi^{u} Q^{u}-r}{t} d t+\left[Q^{u}(t-p f)\right] d \psi^{u} .
$$


Now the total effect of the royalty rate and the royalty exemption level on reported harvesting can be written explicitly as,

$$
d \psi^{u}=\psi_{t}^{u} d t+\psi_{r}^{u} d r
$$

Substituting the RHS of (22) for the $d r$ term in (23) gives the effect of changing royalty progression on reported harvesting, holding expected tax revenue constant,

$$
\left.\frac{d \psi^{u}}{d t}\right|_{d R^{e u}=0}=\frac{\psi_{t}^{u}+\psi_{r}^{u} \frac{\left(\psi^{u} Q^{u}-r\right)}{t}}{1-\psi_{r}^{u}[t-p f] Q^{u}}
$$

The denominator of (24) is positive because we previously showed $\psi_{r}^{u} \leq 0$, and we also know that for an interior solution, $t-p f>0$. Concerning the numerator, we can write it using comparative statics and the first-order condition (10), i.e.,

$$
\psi_{t}^{u}+\psi_{r}^{u} \frac{\left(\psi^{u} Q^{u}-r\right)}{t}=\left(E U_{\psi^{u} \psi^{u}}\right)^{-1}\left[(1-p) u^{\prime}\left(Y^{u}\right)+p U^{\prime}\left(Z^{u}\right)\right]<0
$$

Using (25) in (24), we see that $\left.\frac{d \psi^{u}}{d t}\right|_{d R^{e u}=0}=\frac{\psi_{t}^{u}+\psi_{r}^{u} \frac{\left(\psi^{u} Q^{u}-r\right)}{t}}{1-\psi_{r}^{u}[t-p f] Q^{u}}<0$. Summarizing we have,

Proposition 3. Under a penalty scheme where the fine is assessed against undeclared harvesting, higher royalty progression, which keeps expected royalty collection revenues constant, will decrease reported harvesting and thereby increase cheating.

Proposition 3 leads to a completely different conclusion than in the case where penalties are levied against evaded royalty payments (Proposition 2). When the penalty rate is charged on 
undeclared harvesting volume, an increase in the royalty rate will induce positive income and negative substitution effects on reported harvesting, while the royalty tax exemption change will induce a negative income effect. Thus, a tax-revenue neutral increase in royalty progression will have a net negative substitution effect, thereby increasing cheating and underreporting of harvest volumes from the concession.

According to Proposition 3, lower royalty progression will increase reported harvesting. This suggests that a regressive royalty system with a minimum lump-sum fee is the proper design to decrease cheating when the fine is assessed against undeclared harvesting. We demonstrate this formally in Appendix 4. Thus, this penalty case is now consistent with the suggestion in the literature noted earlier regarding royalty reform.

\section{Tax-Revenue Neutral Royalty Progression and Actual Harvesting}

Much of the literature discusses the role of royalties in changing actual harvesting, i.e., proposing for instance that royalties should be increased in order to reduce deforestation and concession-based harvest expansion, or to allow governments to capture greater rents from concession harvests. The previous section considered reported harvesting, which is of course an important component of cheating and resulting penalties. We now focus on incentives concerning the harvester's choice of actual harvesting. Like above we ask the following policy question: what is the effect of a change on royalty progression on actual harvesting, undertaken to hold expected royalty collection revenues constant? Again, we consider both the case of penalties levied on evaded royalties and undeclared harvesting.

\section{A. Penalty Charged on Evaded Royalties}

Expected royalty revenues are now written as, 


$$
R^{e}=t Q[\psi+p f(1-\psi)]-t r
$$

Proceeding as above, we obtain,

$$
\left.d r\right|_{d R^{e}=0}=\frac{R^{e}}{t^{2}} d t+\left[\psi+p f(1-\psi)+(1-p f) \psi_{Q} Q\right] d Q
$$

so that the difference here compared to the earlier case is that now we have to consider changes in reported harvesting that arise from changes in actual harvesting. The total effect of the royalty rate $t$ and the exemption level on actual harvesting is given by the following total derivative,

$$
d Q=Q_{t} d t+Q_{r} d r
$$

Using (27) in (28) gives the effect of changing royalty progression on actual harvesting, holding expected royalty revenues constant,

$$
\left.\frac{d Q}{d t}\right|_{d R^{e}=0}=\frac{Q_{t}+Q_{r} \frac{R^{e}}{t^{2}}}{\left[1-Q_{r}\left[\psi+(1-\psi) p f+(1-p f) \psi_{Q} Q\right]\right.}
$$

The second term in the denominator is positive because, as we showed previously, $Q_{r} \geq 0$ and at an interior solution, $(1-p f)>0$ and $\psi+p f(1-\psi)+(1-p f) \psi_{Q} Q>0$ because $\psi_{Q}>0$. We continue under the plausible assumption that the total expression in the denominator is positive.

The numerator can be expressed as follows, 
$Q_{t}+Q_{r} \frac{R^{e}}{t^{2}}=\left(E U_{Q Q}^{*}\right)^{-1}\left\{(1-p) U^{\prime}\left(Y^{*}\right) \psi+p U^{\prime}\left(Z^{*}\right)(\psi+(1-\psi) f)\right.$

$\left.+(\psi Q-r)(1-p) U^{\prime}\left(Y^{*}\right) \hat{a}\left[A\left(Z^{*}\right)(1+x)-A\left(Y^{*}\right)\right]-(1-p) U^{\prime}\left(Y^{*}\right) \hat{a}\left[A\left(Z^{*}\right)-A\left(Y^{*}\right)\right] \frac{R^{e}}{t}\right\}$

where $x=f(1-\psi) Q /(\psi Q-r)$. Using this definition and equation (26) we can simplify the term in braces to obtain,

$$
-\left[(1-p) U^{\prime}\left(Y^{*}\right) \psi+p U^{\prime}\left(Z^{*}\right)(\psi+t(1-\psi))\right]<0
$$

Now, using (31) together with (29), we obtain, $\left.\frac{d Q}{d t}\right|_{d R^{e}=0}<0$. We summarize this in the following:

Proposition 4. Under a penalty scheme where the fine is levied against evaded royalty payments, higher royalty progression, implemented to keep expected royalty collection revenues constant, will decrease actual harvesting.

According to Proposition 4 royalty rates should be higher if exemptions are also increased, as long as the objective is to reduce deforestation and still keep royalty revenues collected by the government constant. This policy package reduces actual harvesting. The economic interpretation is straightforward. A higher royalty rate has negative substitution and income effects on actual harvesting, while a higher royalty exemption level, used to keep tax collection constant, has a positive income effect. Thus, if the government keeps expected royalty collection revenues constant, the income effects vanish and the negative substitution effect remains. Note also that if actual harvesting tends to be larger than the size of the concession awarded by the government to the harvester, i.e., we have another form of illegal logging present, then higher progression could be used to reduce it. 


\section{B. Penalty Charged on Undeclared Harvest}

Finally, we consider the second type of penalty scheme. Proceeding as before, expected royalty collection revenues are written for this penalty scheme as,

$$
R^{e u}=Q^{u}\left[t \psi^{u}+p f\left(1-\psi^{u}\right)\right]-t r .
$$

Analogous to the earlier case, we first derive the total derivative of expected revenues (32) with respect to the exemption level, royalty rate, and actual harvesting, taking the relationship between actual and reporting harvesting into account. Then, we solve for $\left.d r\right|_{d R^{e u}=0}$, which depends on finding the expression for the total derivative of actual harvesting, $d Q^{u}=Q_{t}^{u} d t+Q_{r}^{u} d r$. Finally, we substitute from the former into the latter and obtain,

$$
\left.\frac{d Q^{u}}{d t}\right|_{d R^{e u}=0}=\frac{Q_{t}^{u}+Q_{r}^{u} \frac{\left(\psi^{u} Q^{u}-r\right)}{t}}{1-Q_{r}^{u}\left[t \psi^{u}+p f\left(1-\psi^{u}\right)+Q^{u} \psi_{Q u}^{u}(t-p f)\right]}
$$

In the denominator, $Q_{r} \geq 0, \psi_{Q^{u}}^{u}>0$, and $t-p f>0$. We assume that the denominator is positive from hereon. For the numerator, we can follow procedures similar to the derivation of (27) - (31) and obtain,

$$
Q_{t}^{u}+Q_{r}^{u} \frac{\left(\psi^{u} Q^{u}-r\right)}{t}=\left(E U_{Q^{u} Q^{u}}^{u^{*}}\right)^{-1}\left\{\left[(1-p) U^{\prime}\left(Y^{u}\right)+p U^{\prime}\left(Z^{u}\right)\right] \psi^{u}<0\right.
$$

This implies,

$$
\left.\frac{d Q^{u}}{d t}\right|_{d R^{e u}=0}<0
$$


We now finally have,

Proposition 5. Under a penalty scheme where the fine is assessed against undeclared harvesting, higher royalty progression, which holds expected royalty collection revenues constant, will decrease actual harvesting.

The interpretation of Proposition 5 is similar to Proposition 4. Both show that the effect of taxrevenue neutral royalty progression is to reduce actual harvesting under both penalty schemes, unlike in the case of reported harvesting. In Appendix 4 we show that a regressive tax-revenue neutral reform, that increases the lump sum fee and compensates it by decreasing the royalty rate, will increase actual harvesting. Thus, the desirability of the suggested combination of a lumpsum fee and a royalty rate very much depends on whether unreported harvesting is the only form of illegal logging or not. If it is, then a regressive tax system performs best, because it reduces unreported harvesting and intensifies the use of the concession. If the harvester has an incentive to harvest more than the concession right allows, then a regressive system is less desirable.

\section{Conclusions}

In this paper we study royalty reform in economies with forest concessions. This has become an important issue in the forestry literature, as it has been argued that royalties applied to concessions harvesting are too low, and that they do not allow enough rent capture by the government, thus creating incentives for deforestation. We develop a tax evasion model to examine the suggested reform towards a combination of a forest fee or subsidy applied to a concession right and a higher royalty rate on harvesting. This model allows us to ask how progression or regression of this combination can be used to decrease illegal harvesting activities in the important case where expected government revenues remain at constant levels. Our analysis is the first to examine royalty reform in a context of illegal logging-related activities, when cheating might not be perfectly detected by the government. 
A critical part of our analysis is to understand the incentive for harvesters to engage in illegal (underreporting) of harvest volumes, which is a common problem throughout the world in developing economies with concessions. We examine how royalty reform affects reported harvesting and actual harvesting of a concession under two different penalty schemes, where the cheating harvester when detected must pay either a fine based on the evaded royalty payment, or one based on undeclared harvesting.

We model the linkages between concession harvesting, cheating and detection in three stages. Actual harvest volume is decided upon by the harvester in the first stage. In the second stage, the harvester chooses what fraction of actual harvesting is reported to the government for royalty payment. Finally, the harvester's uncertainty regarding detection or non-detection of cheating by the government is revealed.

We show that while higher royalty tax progression serves to decrease actual harvesting independent of the penalty scheme, its effect on reported harvesting is sensitive to the penalty scheme. In particular, under a penalty scheme where the fine is levied on evaded royalty payments, an increase in royalty progression that holds expected government revenues constant will increase reported harvesting and decrease cheating by concession harvesters. However, when the penalty scheme has the fine levied on undeclared harvesting, the reverse happens; a rise in revenue-neutral royalty progression will decrease reported harvesting. In this case, more appropriate reform is a regressive royalty system, because higher regression will increase reported harvesting.

These results add to the current policy debate surrounding royalties and help us assess the often-suggested reform of royalty systems towards a combination of a minimum lump-sum fee and a royalty rate. Obviously, this suggestion has some merit, but we have demonstrated that this combination should be progressive or regressive depending on the penalty scheme implemented with the royalty system, and depending on the possible under- or over-use of the concession rights by the harvester. Illegal logging, i.e. harvesting more than the concession right permits, 
can be reduced by a progressive royalty system. Under-use of the concession right can be corrected by a regressive tax system. Thus, there is considerable scope to taylor royalty systems to the particulars of each country and the characteristics of illegal logging in the country.

In our paper we have focused royalty reform analysis by keeping expected royalty collection fixed, and we have assumed an exogenous probability of detection and penalty by the government. The first assumption is important because it provides incentive for poor developing country governments to reform royalties. In future work, it would be interesting to treat enforcement as a potential policy instrument. In that case, one could ask how the government should jointly design royalties and enforcement schemes to both capture rents from concession harvesting, control illegal logging-related activities, and limit deforestation. 


\section{Appendix 1: Second-order conditions of reported and actual harvesting}

\section{Reported harvesting}

\section{A. Fine levied on evaded royalty payments}

The second order condition for the choice of reported harvesting is, $E U_{\psi \psi}=(-1-p) U^{\prime \prime}(Y) t Q+p(f-1)^{2} U^{\prime \prime}(Z) t Q<0$. Using equation (9) and the definition of absolute risk aversion, $A(.) \equiv-U^{\prime \prime}(.) / U^{\prime}($.$) to rewrite the marginal utilities, we can show that$ the second order condition for a maximum holds,

$$
E U_{\psi \psi}=-(1-p) U^{\prime}(Y) t Q[A(Y)+(f-1) A(Z)]<0
$$

\section{B. Fine levied on undeclared harvesting}

The second order condition is

$E U_{\psi^{u} \psi^{u}}=\left[(1-p) U^{\prime \prime}\left(Y^{u}\right) t^{2}+p(f-t)^{2} U^{\prime \prime}\left(Z^{u}\right)\right] Q^{u}<0$. Using $p(f-t)=\frac{(1-p) U\left(Y^{u}\right) t}{U\left(Z^{u}\right)}$ and making use of the definition of absolute risk aversion we have,

$$
E U_{\psi^{u} \psi^{u}}=-Q^{u}(1-p) U^{\prime}\left(Y^{u}\right) t\left[A\left(Y^{u}\right) t+(f-t) A\left(Z^{u}\right)\right] Q^{u}<0
$$

\section{Actual harvesting}

\section{A. Fine levied on evaded royalty payments}

The second order condition becomes, $E U_{Q Q}^{*}=(1-p) U^{\prime \prime}\left(Y^{*}\right) \hat{a}^{2}+p U^{\prime \prime}\left(Z^{*}\right) \hat{b}^{2}-\left[(1-p) U^{\prime}\left(Y^{*}\right)+p U^{\prime}\left(Z^{*}\right)\right] C^{\prime \prime}(Q)$. From the firstorder condition $p \hat{b}=\frac{-(1-p) U^{\prime}\left(Y^{*}\right) \hat{a}}{U^{\prime}\left(Z^{*}\right)}$ and using absolute risk aversion as before, we have

$$
E U_{Q Q}^{*}=(1-p) U^{\prime}\left(Y^{*}\right) \hat{a}\left[A\left(Z^{*}\right) \hat{b}-A\left(Y^{*}\right) \hat{a}\right]-\left[(1-p) U^{\prime}\left(Y^{*}\right)+p U^{\prime}\left(Z^{*}\right)\right] C^{\prime \prime}(Q)<0 \quad \text { A.3 }
$$

\section{B. Fine levied on undeclared harvesting}

Using the interior solution $p \widetilde{b}=\frac{-(1-p) U^{\prime}\left(Y^{u}\right) \widetilde{a}}{U\left(Z^{u}\right)}$ and the definition of absolute risk aversion we have,

$$
E U_{Q^{u} Q^{u}}^{u^{*}}=(1-p) U^{\prime}\left(Y^{u}\right) \widetilde{a}[A(Z u) \tilde{b}-A(Y u) \widetilde{a}]-\left[(1-p) U^{\prime}\left(Y^{u}\right)+p U^{\prime}\left(Z^{u}\right)\right] C^{\prime \prime}\left(Q^{u}\right)<0 \text { A.4 }
$$




\section{Appendix 2. Comparative statics of reported harvesting}

\section{A. Fine levied on evaded royalty payments}

Obtaining the partial derivative of (7) with respect to the Q (exogenous in the second stage), using (9), and making use of the definition of absolute risk aversion, we have,

$E U_{\psi Q}=-(1-p) U^{\prime}(Y)\left[\frac{U^{\prime \prime}(Y)}{U^{\prime}(Y)} a-\frac{U^{\prime \prime}(Z)}{U^{\prime}(Z)} b\right]=-(1-p) U^{\prime}(Y)[A(Z) b-A(Y) a]>0$, A.5

where $a$ and $b$ are defined in the text. Using A.1, the effect of a change in actual harvesting on reported harvesting can be expressed as,

$\psi_{Q}=-\frac{E U_{\psi Q}}{E U_{\psi \psi}}=\frac{A(Y) a-A(Z) b}{t Q[A(Y)+(f-1) A(Z)]}$,

Under DARA higher actual harvesting increases reported harvesting and the same happens under CARA, when $\psi_{Q}=\frac{(1-\psi)}{Q}>0$.

For the tax exemption we have the following cross partial derivative using (7),

$$
E U_{\psi r}=-(1-p) U^{\prime \prime}(Y) t+p(f-1) U^{\prime \prime}(Z) t
$$

Using the definition of absolute risk aversion and equation (9) to rewrite equation (A.7), we have

$$
\psi_{r}=-\frac{E U_{\psi r}}{E U_{\psi \psi}}=\frac{t[A(Y)-A(Z)]}{t Q[A(Y)+(f-1) A(Z)]}
$$

The sign of equation A.8 depends on risk aversion behavior. Under CARA $\psi_{r}=0$, but under DARA, $\psi_{r}<0$, so that a higher exemption will decrease reported harvesting.

Finally, for the royalty rate we have from (7),

$$
E U_{\psi t}=(1-p) U^{\prime \prime}(Y) \psi Q-p(f-1) U^{\prime \prime}(Z) Q[\psi+(1-\psi) f]
$$

Thus, the effect of the royalty rate is given by,

$$
\psi_{t}=-\frac{E U_{\psi t}}{E U_{\psi \psi}}=\frac{-A(Y) Q \psi+A(Z) Q(\psi+(1-\psi) f)}{t Q[A(Y)+(f-1) A(Z)]},
$$

where again we have made use of (9) and absolute risk aversion. The numerator of A.10 is positive when $A^{\prime}()<$.0 and $\psi \leq 1$. Thus under DARA, a rise in the royalty rate increases reported harvesting, while under CARA it simplifies to $\psi_{t}=\frac{(1-\psi)}{t}>0$.

\section{B. Fine levied on undeclared harvesting}

For the impact of actual harvesting we have the following cross partial derivative, 


$$
\begin{aligned}
E U_{\psi^{u} Q^{u}}=- & (1-p) t U^{\prime \prime}\left(Y^{u}\right)\left[q-C^{\prime}\left(Q^{u}\right)-t \psi^{u}\right] \\
& +p(f-t) U^{\prime \prime}\left(Z^{u}\right)\left[q-C^{\prime}\left(Q^{u}\right)-t \psi^{u}-f\left(1-\psi^{u}\right)\right]
\end{aligned},
$$

where, $a^{u}$ and $b^{u}$ are defined in the text. Equation A.11 can be rewritten, using absolute risk aversion and the first-order condition (11) as

$$
E U_{\psi^{u} Q^{u}}=-(1-p) U^{\prime}\left(Y^{u}\right) t\left[A\left(Z^{u}\right) b^{u}-A\left(Y^{u}\right) a^{u}\right]
$$

Thus the effect of actual harvesting is given by,

$\psi_{Q^{u}}^{u}=-\frac{E U_{\psi^{u} Q^{u}}}{E U_{\psi^{u} \psi^{u}}}=\frac{A\left(Y^{u}\right) a^{u}-A\left(Z^{u}\right) b^{u}}{t Q^{u}\left[A\left(Y^{u}\right) t+(f-t) A\left(Z^{u}\right)\right]}>0$

Under DARA, $\psi_{Q^{u}}^{u}>0$, and under CARA,

$$
\psi_{Q^{u}}^{u}=\frac{a^{u}-b^{u}}{t Q^{u} f}=\frac{f\left(1-\psi^{u}\right)}{t Q^{u} f}=\frac{\left(1-\psi^{u}\right)}{t Q^{u}}>0
$$

Next we consider a effect of the royalty exemption level. We obtain,

$$
E U_{\psi^{u}{ }_{r}}=-t^{2}(1-p) U^{\prime}\left(Y^{u}\right)\left[A\left(Z^{u}\right)-A\left(Y^{u}\right)\right]
$$

Thus we have,

$$
\psi_{r}^{u}=\frac{-E U_{\psi^{u} r}}{E_{\psi^{u} \psi^{u}}}=\frac{t\left[A\left(Y^{u}\right)-A\left(Z^{u}\right)\right]}{Q^{u}\left[A\left(Y^{u}\right) t+A\left(Z^{u}\right)(f-t)\right]} .
$$

Under DARA, the sign A.16 is negative, while it equals zero under CARA.

Finally, for $t$ we use again $p(f-t)=\frac{(1-p) U^{\prime}\left(Y^{u}\right) t}{U^{\prime}\left(Z^{u}\right)}$ to obtain

$$
E U_{\psi^{u} t}=-\left[(1-p) U^{\prime}\left(Y^{u}\right)+p U^{\prime}\left(Z^{u}\right)\right]+p(f-t) U^{\prime}\left(Z^{u}\right)\left(\psi^{u} Q^{u}-r\right)\left[A\left(Z^{u}\right)-A\left(Y^{u}\right)\right]
$$

Thus we have,

$$
\psi_{t}^{u}=\frac{-E U_{\psi^{u} t}}{E U_{\psi^{u} \psi^{u}}}=\frac{\left[(1-p) U^{\prime}\left(Y^{u}\right)+p U^{\prime}\left(Z^{u}\right)\right]+p(f-t) U^{\prime}\left(Z^{u}\right)\left(\psi^{u} Q^{u}-r\right)\left[A\left(Z^{u}\right)-A\left(Y^{u}\right)\right]}{-(1-p) U^{\prime}\left(Y^{u}\right) t Q^{u}\left[A\left(Y^{u}\right) t+(f-t) A\left(Z^{u}\right)\right]}
$$

The first bracketed term in the numerator represents the substitution effect that follows from the royalty instrument. Given the penalty scheme, the royalty causes a distortion to the harvester's choice of reported harvesting. $\psi_{t}^{u}$ is ambiguous under DARA, and negative under CARA.

\section{Appendix 3. Comparative statics of actual harvesting}

A. Fine levied on evaded royalty payments

First consider the cross partial derivative of EU* with respect to both $t$ and $r$, 
$E U_{Q r}^{*}=t\left[(1-p) U^{\prime \prime}\left(Y^{*}\right) \hat{a}+p U^{\prime \prime}\left(Z^{*}\right) \hat{b}\right]$

Making use of (15) and the absolute risk aversion measure, we can rewrite A.19 as, $E U_{Q r}^{*}=t(1-p) U^{\prime}\left(Y^{*}\right) \hat{a}\left[A\left(Z^{*}\right)-A\left(Y^{*}\right)\right]$

The effect of the royalty exemption $r$ on actual harvesting $Q$ is given by,

$Q_{r}=-\frac{E U_{Q r}^{*}}{E U_{Q Q}^{*}}=\frac{-t(1-p) U^{\prime}\left(Y^{*}\right) \hat{a}\left[A\left(Z^{*}\right)-A\left(Y^{*}\right)\right]}{(1-p) U^{\prime}\left(Y^{*}\right) \hat{a}\left[A\left(Z^{*}\right) \hat{b}-A\left(Y^{*}\right) \hat{a}\right]-\left[(1-p) U^{\prime}\left(Y^{*}\right)+p U^{\prime}\left(Z^{*}\right)\right] C^{\prime \prime}(Q)}$

Thus, actual harvesting increases as the exemption level is raised under DARA, but under CARA $Q_{r}=0$.

Next we examine how actual harvesting responds to the royalty rate,

$$
\begin{aligned}
E U_{Q t}^{*}=-\left[(1-p) U^{\prime}\left(Y^{*}\right) \psi+p U^{\prime}\left(Z^{*}\right)(\psi+t(1-\psi))\right]- \\
(1-p) U^{\prime \prime}\left(Y^{*}\right) \hat{a}(\psi Q-r)-p U^{\prime \prime}(Z) \hat{b}(\psi Q-r+f(1-\psi) Q)
\end{aligned}
$$

Making use of (15) again, $E U_{Q t}^{*}$ can be written,

$$
\begin{aligned}
& E U_{Q t}^{*}=-[\left.(1-p) U^{\prime}\left(Y^{*}\right) \psi+p U^{\prime}\left(Z^{*}\right)(\psi+t(1-\psi))\right]- \\
&(\psi Q-r)(1-p) U^{\prime}\left(Y^{*}\right) \hat{a}\left[A\left(Z^{*}\right)(1+x)-A\left(Y^{*}\right)\right]
\end{aligned}
$$

where $x=\frac{f(1-\psi) Q}{\psi Q-r}>0$. Thus, $E U_{Q t}^{*}<0$, so that $Q_{t}<0$ for $A^{\prime}() \leq$.0 .

\section{B. Fine levied on undeclared harvesting}

For the tax exemption, we need to compute the following cross partial derivative,

$E U_{Q^{u} r}^{u^{*}}=t\left[(1-p) U^{\prime \prime}\left(Y^{u}\right) \tilde{a}+p U^{\prime \prime}\left(Z^{u}\right) \tilde{b}\right]$

Using (32) gives,

$E U_{Q^{u} r}^{u^{*}}=t(1-p) U^{\prime}\left(Y^{u}\right) \widetilde{a}\left[A\left(Z^{u}\right)-A\left(Y^{u}\right)\right]$,

which is positive under DARA and zero under CARA. This implies that the impact of an increase in the exemption level on actual harvesting depends on absolute risk aversion,

$Q_{r}^{u}=\frac{-E U_{Q^{u} r}^{u^{*}}}{E U_{Q u Q u}^{u^{*}}}>0$ if $A^{\prime}()<$.0 and $\frac{-E U_{Q^{u} r}^{u^{*}}}{E U_{Q u Q u}^{u^{*}}}=0$ if $A^{\prime}()=$.

Comparing A. 25 with A.21 we see that the penalty scheme does not matter in terms of the effect of exemption levels on actual harvesting. is given by,

The impact of the royalty rate can be derived using procedures similar to A.23 - A.25 and

$$
Q_{t}^{u}=\frac{-E U_{Q^{u} t}^{u^{*}}}{E U_{Q u Q u}^{u^{*}}}<0 \text { if } A^{\prime}(.)<0 \text { and } \frac{-E U_{Q^{u} t}^{u^{*}}}{E U_{Q u Q u}^{u^{*}}}=0 \text { if } A^{\prime}(.)=0
$$

\section{Appendix 4. Regressivity and the fine on undeclared harvesting}

\section{A. Reported harvesting}

The objective function of the harvester is,

$$
\underbrace{\operatorname{Max}}_{\psi^{u}} E U=(1-p) U(Y)+p U(Z) \text {, }
$$


where $Y=Q^{u}\left(q-t \psi^{u}\right)-c\left(Q^{u}\right)-r, Z=Y-f Q^{u}\left(1-\psi^{u}\right), t$ is the royalty tax rate and $r$ is the lump-sum forest fee. The first-order conditions are

$E U_{\psi^{u}}=0 \Leftrightarrow-(1-p) t U^{\prime}(Y)+p(f-t) U^{\prime}(Z)=0$,

and the interior solution implies $t-p f>0$. The second-order condition is

$E U_{\psi^{u} \psi^{u}}=-(1-p) U^{\prime}(Y) t Q[A(Y) t+(f-t) A(Z)]<0$.

For the lump sum fee and the royalty tax rate we have

$\psi_{r}^{u}=\frac{-t(1-p) U^{\prime}(Y)[A(Z)-A(Y)]}{E U_{\psi^{u} \psi^{u}}}\left\{\begin{array}{l}> \\ =\end{array}\right\}$ if $A^{\prime}\left\{\begin{array}{l}< \\ =\end{array}\right\} 0$

$\psi_{t}^{u}=\frac{\left[(1-p) U^{\prime}(Y)+p U^{\prime}(Z)\right]-p(f-t) U^{\prime}(Z) \psi^{u} Q^{u}[A(Z)-A(Y)]}{E U_{\psi^{u} \psi^{u}}}\left\{\begin{array}{l}? \\ <\end{array}\right\}$ if $A^{\prime}\left\{\begin{array}{l}< \\ =\end{array}\right\} 0$

The government's expected tax revenue is,

$R^{e}=Q^{u}\left[t \psi^{u}+p f\left(1-\psi^{u}\right]+r\right.$

The changes in taxes and reported harvesting, which will keep A.30 constant, are given by,

$d R^{e}=0=d r+\psi^{u} Q^{u} d t+Q^{u}(t-p f) d \psi^{u}$, so that

$\left.d r\right|_{d R^{e}=0}=-\psi^{u} Q^{u} d t-Q^{u}(t-p f) d \psi^{u}$. Substituting the RHS of above equation

for $d r$ in the equation $d \psi^{u}=\psi_{t}^{u} d t+\psi_{r}^{u} d r$ gives,

$\left.\frac{d \psi^{u}}{d t}\right|_{d R^{e}=0}=\frac{\psi_{t}^{u}-\psi^{u} Q^{u} \psi_{r}^{u}}{\left[1+\psi_{r}^{u}(t-p f) Q^{u}\right]}$,

where the denominator is positive because $\psi_{r}^{u} \geq 0$ and $t-p f>0$ at the interior solution. In terms of the numerator we have,

$\psi_{t}^{u}-\psi^{u} Q^{u} \psi_{r}^{u}=\left(E U_{\psi \psi}\right)^{-1}\left[(1-p) U^{\prime}(Y)+p U^{\prime}(Z)\right]<0$, so that

$\left.\left.\frac{d \psi^{u}}{d t}\right|_{d R^{e}=0}=\frac{\psi_{t}^{u}-\psi^{u} Q^{u} \psi_{r}^{u}}{\left[1+\psi_{r}^{u}(t-p f) Q^{u}\right.}\right]^{<0}$

The tax scheme is regressive because the average tax rate decreases with the reported tax base, i.e. $R=t \psi^{u} Q^{u}+r$ so that $\frac{R}{\psi^{u} Q^{u}}=t+\frac{r}{\psi^{u} Q^{u}}$. The higher is the lump-sum fee $r$, the more regressive is the tax scheme. Thus, a higher lump-sum 
fee level $r$ compensated by a lower royalty rate $t$ will increase the reported harvesting.

\section{B. Actual harvesting}

The first-order condition for actual harvesting due to the envelope theorem can be written as

$E U_{Q^{u}}=0 \Leftrightarrow(1-p) U^{\prime}\left(Y^{u}\right) \widetilde{a}+p U^{\prime}\left(Z^{u}\right) \widetilde{b}=0$,

where $\tilde{a}=q-c^{\prime}\left(Q^{u}\right)-t \psi^{u}>0$ and $\tilde{b}=q-c^{\prime}\left(Q^{u}\right)-\left(t \psi^{u}+f\left(1-\psi^{u}\right)\right)<0$.

The second-order condition is $E U_{Q^{u} Q^{u}}<0$.

The cross-derivatives of the first-order condition with respect to for the lump-sum fee $r$ and for the royalty rate $t$, respectively, are

$$
\begin{aligned}
& E U_{Q^{u} r}=(1-p) U^{\prime}\left(Y^{u}\right) \widetilde{a}\left[A\left(Y^{u}\right)-A\left(Z^{u}\right)\right] \leq 0 \quad \text { as } A^{\prime} \leq 0 \\
& E U_{Q^{u} t_{t}}=\psi^{u} Q^{u} E U_{Q^{u} r}-\left[(1-p) U^{\prime}\left(Y^{u}\right)+p U^{\prime}\left(Z^{u}\right)\right] \psi^{u}<0 \quad \text { as } A^{\prime} \leq 0 \quad \text { A.34b }
\end{aligned}
$$

Hence, $Q_{r}^{u} \leq 0$ as $A^{\prime} \leq 0$ and $Q_{t}^{u}<0$ as $A^{\prime} \leq 0$

The government's expected tax revenue is,

$$
R^{e u}=Q^{u}\left[t \psi^{u}+p f\left(1-\psi^{u}\right]+r\right.
$$

The changes in taxes and actual harvesting, which will keep A.35 constant are

$$
\left.d r\right|_{d R^{e}=0}=-\psi^{u} Q^{u} d t-\left[t \psi^{u}+p f\left(1-\psi^{u}\right)+(t-p f) Q^{u} \psi_{Q^{u}}^{u}\right] d Q^{u} .
$$

Substituting the RHS of above equation for $d r$ in $d Q^{u}=Q_{t}^{u} d t+Q_{r}^{u} d r$ gives,

$$
\left.\frac{d Q^{u}}{d t}\right|_{d R^{e u}=0}=\frac{Q_{t}^{u}-\psi^{u} Q^{u} Q_{r}^{u}}{\left[1+Q_{r}^{u}\left[t \psi^{u}+p f\left(1-\psi^{u}\right)+(t-p f) Q^{u} \psi_{Q^{u}}^{u}\right]\right]},
$$

where the denominator is assumed to be positive under $A^{\prime} \leq 0$. In terms the numerator, A.34a and A.34b indicate that $Q_{t}^{u}-\psi^{u} Q^{u} Q_{r}^{u}=\left(E U_{Q^{u} Q^{u}}\right)^{-1}\left[(1-p) U^{\prime}\left(Y^{u}\right)+p U^{\prime}\left(Z^{u}\right)\right] \psi^{u}<0$, so that $\left.\frac{d Q^{u}}{d t}\right|_{d R^{e u}=0}<0$

Hence a higher lump-sum fee level $r$ compensated by a lower royalty rate $t$ will increase the actual harvesting, as discussed after Proposition 5. 


\section{References}

Allingham, M.G. and A. Sandmo. 1972. Income Tax Evasion: A Theoretical Analysis, Journal of Public Economics, 1, 323-338.

Amacher, G.S.,R.J. Brazee and M. Witvliet. 2001. Royalty Systems, Government Revenues, and Forest Condition: An Application from Malaysia, Land Economics, 77(2), 300-313.

Arrow, K.J. 1970. Essays in the Theory of Risk-Bearing, North-Holland, Amsterdam.

Boscolo, M. and J. R. Vincent. 2000. Promoting Better Logging Practices in Tropical Forests: A Simulation Analysis of Alternative Regulations, Land Economics, 76(1), 1-14.

Bushbacher, R. 1990. National Forest Management in the Humid Tropics: Ecological, Social and Economic Considerations, Ambio 19(5):253-258.

Clarke, H.R., W.J. Reed and R.M. Shestra. 1993. Optimal Enforcement of Property Rights on Developing Country Forests Subject to Illegal Logging, Resource and Energy Economics, 15. 271-293.

Cowell, F. 1987. The economic analysis of tax evasion, in Hey, J., and P. Lambert (eds.) Surveys in the Economics of Uncertainty, Basil Blackwell, Oxford, pp. 173-203.

FAO 1997. Asia-Pacific Forestry Sector Outlook Study. Working Paper No. APFSOS/WP/07, Rome.

Gray, J. 2000. Forest Concession Policies and Revenue Systems: Country Experience and Policy Changes for Sustainable Tropical Forestry, World Bank Technical Paper, Forest Series, Washington D.C.

Grut, M., J. Gray, and N. Egli. 1991. Forest Pricing and Concession Policies, World Bank Discussion Paper, Washington D.C.

Koskela, E. 1983. A Note on Progression, Penalty Schemes and Tax Evasion, Journal of Public Economics, 22, 127-133.

Lambert, P.J. 1993. The Distribution and Redistribution of Income: A Mathematical Analysis, Manchester University Press, $2^{\text {nd }}$ edition. Manchester UK.

Marrelli, M. 1984. On Indirect Tax Evasion, Journal of Public Economics, 25, 181-196.

Milliman, S.R. 1986. Optimal Fishery Management in the Presence of Illegal Activity, Journal of Environmental Economics and Management, 13, 363-381.

Musgrave, R.A. and T. Thin 1948. Income Tax Progression, 1929-48, Journal of Political Economy, 56, 498-511.

Myles, G.D. 1995. Public Economics, Cambridge University Press.

Poore, E. 1993. The Sustainable Management of Tropical Forests: the Issues, in The Earthscan Reader in Tropical Forestry, ed. Rietbergen, London: Earthscan Publications Ltd.

Repetto, R., and M. Gillis (eds.). 1988. Public Policy and the Misuse of Forest Resources. Cambridge: Cambridge University Press.

Sutinen, J.G. and P. Andersen. 1985. The Economics of Fisheries Law Enforcement, Land Economics, 61(4), 387-397.

Walker, R. and T.E. Smith. 1993. Tropical Deforestation and Forest Management under the System of Concession Logging: A Decision-Theoretic Analysis, Journal of Regional Science, 33(3), 387-419.

Yitzhaki, S. 1974. A Note on Income Tax Evasion: A Theoretical Analysis, Journal of Public Economics, 3, 201-202. 